This item was submitted to Loughborough's Research Repository by the author.

Items in Figshare are protected by copyright, with all rights reserved, unless otherwise indicated.

\title{
Working together through sport? Local authority provision for ethnic minorities in the United Kingdom
}

PLEASE CITE THE PUBLISHED VERSION

http://dx.doi.org/10.1080/17430437.2012.690411

PUBLISHER

(c) Taylor \& Francis

VERSION

AM (Accepted Manuscript)

LICENCE

CC BY-NC-ND 4.0

REPOSITORY RECORD

Cleland, Jamie. 2019. "Working Together Through Sport? Local Authority Provision for Ethnic Minorities in the United Kingdom”. figshare. https://hdl.handle.net/2134/12126. 
This item was submitted to Loughborough's Institutional Repository (https://dspace.lboro.ac.uk/) by the author and is made available under the following Creative Commons Licence conditions.

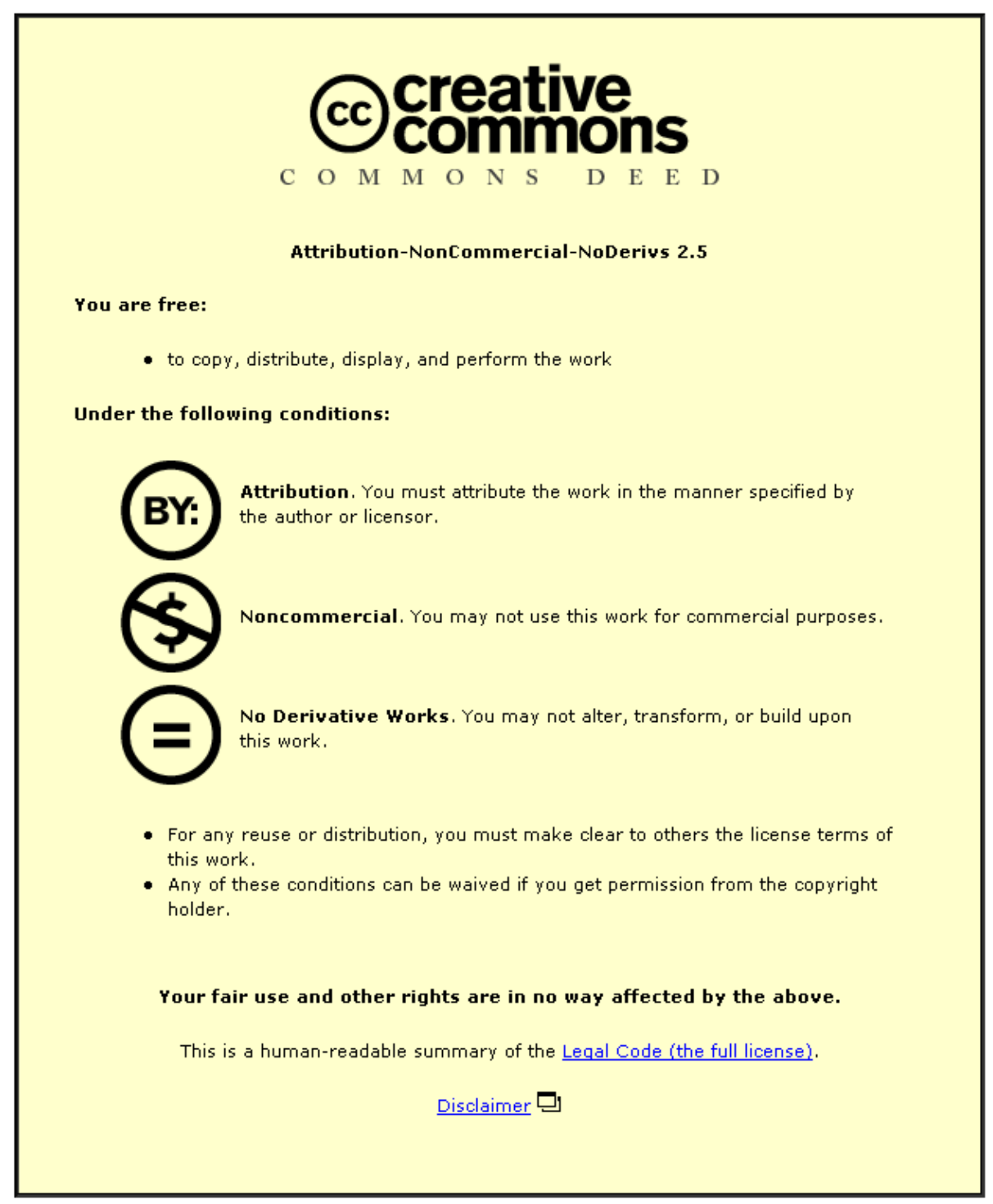

For the full text of this licence, please go to: http://creativecommons.org/licenses/by-nc-nd/2.5/ 
Running Head: Local authority provision for ethnic minorities

\title{
Working Together Through Sport? Local Authority Provision for Ethnic Minorities in the United Kingdom
}

\author{
Jamie A. Cleland \\ Staffordshire University, UK
}

Correspondence concerning this article should be addressed to: Jamie Cleland, Department of Sport and Exercise, Staffordshire University, Leek Road, Stoke-onTrent, ST4 2DF, UK. Tel: +44 (0)1782 294341. Email: j.a.cleland@staffs.ac.uk 


\begin{abstract}
Ethnic minority participation in sport or physical activity has been the subject of recent sociological debate but has received relatively limited empirical analysis. This article assesses the extent to which two local authorities in the United Kingdom, Stoke-on-Trent City Council and East Staffordshire Borough Council, had developed strategies to increase participation rates for ethnic minorities. It draws on sixteen semi-structured interviews with ethnic minority community leaders, local authority employees and a selection of active ethnic minority participants involved in projects in both areas. The results highlight projects established by both local authorities to engage with ethnic minorities and although this is acknowledged as a step forward, racial inequalities and other barriers to participation remain. The article concludes by suggesting that there are still many opportunities for local authorities to work more closely with ethnic minorities to reduce racial inequalities and barriers to participation.
\end{abstract}

Keywords: race; ethnicity; sport; participation; racial inequalities

\title{
Introduction
}

Ethnic minority participation in sport or physical activity in the United Kingdom (UK) is of growing interest. It has been helped by the increasing focus by the national government and local authorities in establishing strategies and projects to improve participation. At the same time, it has also created opportunities for evaluative research to be undertaken to assess how effective these strategies and subsequent projects are in achieving their objectives. Studies have examined ethnic minority participation in various British sports, including cricket and football, but there is a dearth of material which examines local authority leisure provision. ${ }^{1}$ For example, it has been suggested that local authority provision can present confused ideas regarding equal opportunity and race equality and this often leads to inconsistent interpretations of policy. ${ }^{2}$

This article empirically analyses local authority provision for ethnic minorities in two areas of the UK: Stoke-on-Trent and Burton-on-Trent. To do this, it has two objectives: (a) to assess each local authority's level of provision in sport or physical activity for ethnic minorities and (b) to identify if racial inequalities continue to detrimentally affect participation for ethnic minorities. Before it addresses these two objectives, the article firstly engages with the relevant literature on the changes in policy and the academic attention paid to them as well as participation levels and the reported barriers facing ethnic minorities. It then analyses the data collected from sixteen in-depth interviews with ethnic minority community leaders, local authority 
employees and some active ethnic minority participants to offer some explanations on each local authority's level of provision.

Within sociology, the term 'race' is complex as there is a large amount of disagreement over its exact meaning. Burdsey states how some authors place 'race' in inverted commas 'to demonstrate that it is the idea of race that is being referred to and the fact that it has no biological validity'. ${ }^{3}$ For Miles and Brown, 'race' is a meaningless term that reflects class exploitation more than anything else. ${ }^{4}$ Similarly, Garner states that trying to provide a definition of 'race' is impossible as nobody is actually 'white' or 'black' and instead these terms have social meanings rather than biological ones. ${ }^{5}$ Garner argues that there is no consensus regarding dividing lines between different 'races' and by dividing people into 'races' has 'very serious and measurable impacts on people'. ${ }^{6}$ For example, Swinney and Horne state how membership of an ethnic group is not related to the 'colour of skin', as Irish people living in Scotland would be seen as an ethnic minority. ${ }^{7}$ Indeed, these difficulties also affect the gathering of data on sports participation. A survey of sports participation by ethnic group in England, for example, found that a number of respondents did not identify with any of the ethnic categories on the survey. ${ }^{8}$

In terms of the ethnic demographics of both Stoke-on-Trent and Burton-onTrent, the 2001 Census data outlined that for East Staffordshire (where Burton-onTrent is located) the total population was 103,770, with 92 per cent White British, and 4.5 per cent Asian or Asian British. In assessing the wards in Burton-on-Trent where the data was collected, in Anglesey, the total number of residents was 5,835, with 72 per cent White British, and 24 per cent Asian or Asian British. In Shobnall, out of a total of 6,132 residents, 75 per cent were White British with nearly 22 per cent Asian or Asian British. Finally, in Stoke-on-Trent, out of a total number of 240,636 residents, 95 per cent were White British with 3.5 per cent Asian or Asian British. In the Burslem South ward of Stoke-on-Trent where the data was also collected, out of 12,071 residents, 85.5 per cent were White British with nearly 8 per cent Asian or Asian British.

To put the importance of this article in context, in East Staffordshire, the amount of people taking part in thirty minutes of moderately intense sport and active participation at least three days a week had slightly risen from 22.8 per cent in 2005/06 to 23.0 per cent in 2007/08 (the national average was 21.3 per cent). ${ }^{9}$ However, in Stoke-on-Trent, in 2005/06 the figure was 15.8 per cent but had dropped 
to 14.4 per cent in 2007/08. In terms of participation levels for what Sport England term 'non-white adults', the survey highlighted how this had decreased from 18.6 per cent in 2005/06 to just 17.6 per cent in 2007/08 (for 'white adults' it had increased from 21.2 per cent to 21.7 per cent over the same period). ${ }^{10}$ Similarly, for some ethnic minorities across the country less than one in five people are participating just once a month in some form of physical activity. ${ }^{11}$ In fact, it is not just participation levels where ethnic minorities fall behind 'whites'; it is also the case in the levels of volunteering, club membership, tuition and organised competition. ${ }^{12}$

The importance of determining strategies for ethnic minorities is also evidenced by data produced by the 2001 Census. It illustrated how the ethnic minority population grew by 53 per cent from 3.0 million in 1991 to 4.6 million in 2001 (totalling 7.6 per cent of the population). Half of the ethnic minority population were Asians of Indian, Pakistani, Bangladeshi or other Asian origin with a further quarter listed as Black (Black Caribbean, Black African or Other Black). The 2001 Census data also helped to highlight that a greater number of children from ethnic minority groups are more likely to live in deprived areas than white children and thus supports the need for specific, more inclusive, strategies focusing on ethnic minorities to engage them in sport or physical activity. This, therefore, challenges sports organisations and local authorities to work more closely with ethnic minorities in their own communities. However, as the next section highlights there is some difference between the discourse emanating from sports organisations and local authorities and the actual implementation of racial equality policies.

\section{Changes in Policy}

Sports policy in the 1970s tended to concentrate on the development of local leisure centres rather than active participation. Despite the creation of Sport for All during this period, 'race' and ethnicity were not identified as areas requiring specific governmental intervention. Things started to change slightly in the 1980s when the Sports Council, as part of its strategic policy Sport in the Community: The Next Ten Years, targeted specific groups in society where it was felt policy interventions were needed. Here, and somewhat influenced by the political environment at the time (such as the aftermath of the Toxteth and Brixton riots in the early 1980s), black (male) urban youths were prioritised as a disruptive group that needed urgent strategic attention. Despite this, it was not until 1994 when the Sports Council produced a 
policy document titled Black and Ethnic Minorities and Sport that any specific attention was given to the ethnic minority population. However, no sooner had this document been published than the Conservative government at the time outlined a policy titled Sport: Raising the Game, which focused on the development of excellence in the UK's traditional teams sports at the expense of more communitybased initiatives. $^{13}$

To try and force a change in policy, during the 1990s some non-governmental agencies such as governing bodies, fan groups and voluntary organisations all contributed in shaping an awareness of the inequalities faced by ethnic minorities. By way of illustration, in 1993, a successful partnership between football fan groups, the Professional Footballers’ Association and Commission for Racial Equality (CRE) led to the establishment of 'Let's Kick Racism Out of Football'. This particular campaign moved the debate away from 'race' and ethnicity to more of an emphasis on the perpetrators of racism and how the relevant authorities should act in trying to eliminate it. Indeed, its immediate impact began to encourage campaigns in other sports such as 'Hit Racism for Six' in cricket and 'Tackle It - Tackle Racism in Rugby League' (both established in 1996).

From a strategic viewpoint, the UK witnessed the establishment of the Department of Culture, Media and Sport (DCMS), UK Sport, Sporting Equals and Sport Councils like Sport England in the latter part of the 1990s. As part of their wider remit, there has been an increase in policy and strategy with regards to ethnic minorities. Part of this stems from the creation of Sporting Equals in 1998 by Sport England and the CRE to work closely with sport governing bodies and public sector local authorities to develop policies on racial equality. Not long after it was created, Sporting Equals surveyed sixty-two sport governing bodies to analyse how each one approached the importance of achieving racial equality in their organisation. ${ }^{14}$ The results were worrying with half not responding at all, whilst half of those that did stated that racial inequalities were not present in their organisation. In addressing this, in 2000, Sporting Equals published Achieving Racial Equality: A Standard for Sport with the aim of encouraging sports organisations and governing bodies to develop Race Equality Action Plans. ${ }^{15}$ By monitoring the demographics of their participants (such as ethnic origin, age and gender), it provided an opportunity for each organisation to show how it was working towards racial equality objectives (in particular as funding was often attached to it). The aim was to begin the process 
where racial equality became a recognised component of sporting policy. In implementing this, three areas of action were covered: ${ }^{16}$

- commitment, policy, and planning

- participation and public image

- administration and management

Within each area there were three levels of achievement - preliminary, intermediate and advanced. At the lower preliminary level, all organisations were asked to do was to publicly commit to achieving equality, undertake ethnic monitoring and develop policies and procedures. At the higher advanced level, organisations were expected to produce equality training, promote role models and liaise with ethnic minority groups.

Since the introduction of the Equality Standard, equality and diversity in sport has become a key and changing area of sports policy. In 2004 the Sports Equality Standard was introduced, this time also including gender and disability. This was formed through the co-operation of UK Sport and the four UK Sports Councils, the English Federation of Disability Sport, Sporting Equals and the Women's Sport Foundation to highlight a significant commitment towards equality development work for sport providers. Furthermore, in 2007, the Commission for Racial and Human Rights was established through the dissolution of the CRE, the Equal Opportunities Commission and the Disability Rights Commission. This strategy was aimed towards achieving equality, in particular focusing on the commitment of public organisations towards the implementation of policies and practices. Moreover, in 2010, just before Labour lost power a new Equality Act was approved, although at the time of writing this is yet to be officially implemented by the new coalition government.

Indeed, Coalter states that the previous Labour government started two broad approaches in seeking to generate greater social inclusion through policy: firstly, to increase sports participation through area-based targeted programmes in socially deprived areas and, second, to emphasise the contribution which sports volunteering can make to 'active citizenship'. ${ }^{17}$ These projects focused on community initiatives such as improving the health and participation rates amongst different groups of people and backgrounds and tackling drugs, crime and anti-social behaviour. This emphasis on social inclusion led to Sport England establishing an Active Communities programme aimed at providing opportunities for increased participation 
and coaching in areas of social deprivation. Here, volunteering and the promotion of role models helped local authorities develop a number of projects with particular target groups in mind (like ethnic minorities).

The emphasis on equality and inclusion has brought about many changes in a short space of time, but the extent to which racial equality policies have actually been implemented has become a focal point for academic research. In reviewing this area, a consistent theme emerges across many different studies between what sports organisations and local authorities say and what they actually do. ${ }^{18}$ In research conducted by Long et al., for example, racial inequalities existed and policies in this area were not viewed as a high priority if they were faced with other resource demands. ${ }^{19}$ In later work, Long et al. argued that there was an increased recognition within sports organisations to develop better links with ethnic minorities. ${ }^{20}$ However, whilst they found that 62 per cent of sports organisations monitored ethnic minority participants and staff members, only 8 (out of 45 organisations) managed to achieve the preliminary level of the original Standard by June $2003 .{ }^{21}$ In fact, Spracklen et al. drew similar conclusions about the implementation of racial equality policies as nearly all of the governing bodies they researched stated that little had changed in their approach to equity in the preceding 12 months. ${ }^{22}$

In assessing the implementation of equal opportunity policies, Horne and Swinney and Horne examined local authority providers of sport and leisure for black and ethnic minorities in Scotland. ${ }^{23}$ Horne looked to distinguish between those local authorities which had a formal written equal opportunities policy and those which did not. $^{24}$ To help address this, he developed three types of local authority provider in terms of the importance it placed on achieving equality:

- Gestural - organisations which had a policy or policy statement but did not go any further than that;

- Reactive - organisations which were likely to have equality policies in place but would not adequately monitor it and could sometimes be complacent in its approach to equality;

- Proactive - organisations which were likely to be active in challenging racism and sought to achieve its goals regarding equality. 
Horne found that one-third of local authorities in Scotland had not adopted any formal equal opportunity policy and as such only a few local authorities were placed in the proactive category. ${ }^{25}$ This was found to be the case for the more urban communities in Scotland that had higher numbers of black and ethnic minorities. Indeed, similar uneven findings between rhetoric and implementation were also found by Swinney and Horne in their follow-up research in Scotland. ${ }^{26}$ Whilst most local authority respondents indicated that work in the area of racial equality was in progress or planned for the near future, 18 out of the 32 respondents had yet to conduct any research on the sport and leisure requirements of black and ethnic minorities. With similar findings to Horne the authorities viewed as proactive were located in urban areas which were more highly populated by black and ethnic minorities. This led to Swinney and Horne concluding that only minor change had occurred since $1995 .{ }^{27}$ In fact, they described some local authorities as gestural in dealing with ethnic minorities (usually those in more rural areas with very low numbers of black and ethnic minorities). However, the majority of councils did demonstrate an intention towards achieving equality and thus were classified as proactive and reactive.

As well as examining local authorities and sports organisations regarding racial equality policies, there has also been an increasing focus on the power and interests of 'whiteness' and how this is found to prevent managerial intervention to effect change and diversity in society. ${ }^{28}$ The issue of 'race' and its understanding in sport and leisure has been examined elsewhere but a significant recent contribution has been the development of critical race theory (CRT). ${ }^{29}$ Although it originated in North America, Hylton has made a strong case for CRT to be applied more specifically to sport and leisure policy to promote racial equality more effectively. ${ }^{30}$ Hylton argues that 'race' has been marginalised and that by adopting a CRT approach it 'challenges traditional dominant ideologies around objectivity, meritocracy, colourblindness, race-neutrality and equal opportunity'. ${ }^{31}$ For Long and Hylton, it is important to now challenge the power and influence of 'whiteness' when seeking to achieve greater racial equality within sport. ${ }^{32}$

\section{Ethnic Minority Participation in Sport}

Ethnic minorities do not necessarily all share similar lifestyles or cultures, and until recently, there was very little survey work which analysed their patterns of participation in sport or physical activity. Sports Participation and Ethnicity in 
England National Survey 1999/2000 was the first ever large scale quantitative survey (consisting of 3,000 ethnic minority participants) to begin to address this issue. ${ }^{33}$ Highlighting some racial inequalities, the survey helped to highlight the diverse nature of participation levels for men and women from different ethnic minorities. It found that the overall participation rates for ethnic minority groups in sport were 40 per cent compared with a national average of 46 per cent. At a national level the gap in participation between men and women was 15 per cent but for Bangladeshi's it was 27 per cent, Black Africans it was 26 per cent and for Pakistanis it was 20 per cent. It also indicated how Black African men had a higher participation rate than the national average for all men, while Bangladeshi women had participation rates well below the national average for women.

In seeking to encourage greater levels of participation, sports organisations and local authorities are often faced with many diverse barriers which prevent ethnic minorities from taking part in some form of sport or physical activity. In research conducted by Sport England, a lack of money was cited by 25 per cent of Black Caribbean and Black Other as preventing them for participating in sport. ${ }^{34}$ Similarly, 40 per cent of Afro-Caribbean and Indian, and over 80 per cent of Pakistani and Bangladeshi (compared with 28 per cent of the total population) were estimated to live in households with below average income. ${ }^{35}$

In other research, the perceived barriers to low participation for ethnic minorities were culture, gender, age, access to facilities, language, and actual racism or fear of racism. ${ }^{36}$ When asked about sports provision and their access to it, the location of the facility to their home and a lack of appropriate transport were cited as being crucial as to whether they participated. ${ }^{37}$ In similar work, it was stated how Pakistani and Bangladeshi women reported a fear of going out alone due to the risk of actual or potential racist abuse. ${ }^{38}$ This, therefore, can lead to low motivation rates and helps to explain some of the participation findings discussed above.

Most of the research on the barriers to participation tends to focus on girls and women from various Asian cultures. Collins and Kay, for example, found that work, school, childcare and other domestic duties are often stated as preventing ethnic minority women from having sufficient leisure time to participate. ${ }^{39}$ Similar results were also found in the Sports Participation and Ethnicity in England National Survey 1999/2000. ${ }^{40}$ Here, it was reported that over 40 per cent of Indian, Pakistani, Black Caribbean and Black African women felt home and family responsibilities prevented 
them from participating in some form of physical exercise. In comparison to males, Asian parents may put their daughters under greater pressure to care for siblings and help with household tasks such as meal preparation and general cleaning duties.

For some Muslim girls and women, there are other cultural and religious challenges which prevent them from participating in any form of sporting activity. Self-image has been found to play a crucial role as some respondents had stopped attending due to increased internal negative feelings of being seen by other women when getting changed and by men when exercising or attending a particular location. ${ }^{41}$ However, whilst most of the literature on this is applied to Muslim women, it is important to state that this barrier is not just confined to one particular ethnic minority group and that every woman and man interprets their religious requirements differently.

In terms of trying to increase participation rates amongst ethnic minorities, there are many recommendations. ${ }^{42}$ In summarising their research, Carroll et al. recommended using instructors from the ethnic minority group participating, providing free sessions held at the local community centre, having access to a crèche and an extensive local promotion to ensure that the local community were kept informed of physical activities. ${ }^{43}$ Similar recommendations have also been proposed elsewhere on how ethnic minorities can be incorporated better into physical activity initiatives, including better provision provided by local authorities. ${ }^{44}$

\section{Method}

To address the two research objectives, sixteen semi-structured interviews were carried out from February 2009 to May 2009 with individuals in both Stoke-on-Trent and Burton-on-Trent. The aim was to split the participants into three groups and this ultimately proved to be successful: (1) those involved in the community, like community leaders or managers of specific ethnic minority centres; (2) those employed by the local authorities to engage with the local community and develop projects that improve sports participation and physical activity levels; and (3) some ethnic minority participants actually involved in the projects in operation.

To help in recruiting participants into group one a list of names which were known to the County Sports Partnership 'Sport Across Staffordshire and Stoke-onTrent' (SASSOT) was provided and they were subsequently contacted. Initial contact was made by telephone where the research objectives were explained as well as the 
confidential nature of their response and their right of withdrawal. It was also explained that the researcher was white and although access within particular ethnic minority groups proved problematic, enough individuals gave their support for the research to be carried out. Snowball sampling certainly helped and once a face-to-face meeting had taken place the participants were willing to pass on the contact details of other individuals they felt would strengthen the research objectives. ${ }^{45}$ SASSOT also provided the relevant contact details for those individuals in group two and again a telephone call and subsequent face-to-face interview was carried out with representatives of both local authorities. This also helped recruit participants for group three, where permission was given to attend projects directed towards ethnic minorities in both areas. Here, participants were asked if they were willing to participate in the research and those that gave their permission were asked some general questions on the project in which they were involved and their thoughts on local authority provision for ethnic minorities.

As suggested by Carrington and McDonald, although an investigation of this type can be quantitative in nature, 'understanding the subjective experiences of individuals in sports demands a theoretically informed interpretative approach' ${ }^{46}$ Supporting the need for an in-depth qualitative investigation, there is the increasing need for research to analyse how social and cultural factors, including racial ideologies, create and perpetuate differences in society. In doing this, fourteen interviews were carried out face-to-face but the club secretary of Grange Park Rangers (an Asian Sunday league football team in Cobridge, Stoke-on-Trent) and a contact at Madina (an Asian sports club in Burton-on-Trent) both had to be interviewed over the telephone due to work commitments. This was agreed upon to maintain the collection of key data.

In analysing all of the interview data a manual form of content analysis was adopted. Although content analysis can be used quantitatively to count themes in numerical terms, for this article the interview data was themed into categories addressing the two research objectives. Once completed the analysis then began to identify 'patterns and processes, commonalities and differences' within the collected data. ${ }^{47}$ Whilst the findings cannot be deemed representative of all ethnic minorities in Stoke-on-Trent and Burton-on-Trent, they do provide empirical evidence regarding how some ethnic minorities felt about the local projects currently in existence. In fact, 
many of the responses were similar, thus suggesting some commonality across different ethnic minority groups.

\section{Case Study Findings}

As recognised by Coalter, one of the priorities raised within community-based initiatives is the need to engage more widely with ethnic minorities. ${ }^{48}$ Taking a more proactive approach to ethnic minority provision (as identified by Horne), some of the programmes occurring in Burton-on-Trent included those specifically targeting Asian women and in the 2008 summer holidays a project was successfully organised, using Asian coaches, between two local communities (one with a low and one with a high representation of ethnic minorities) to try and encourage the mixing of different cultures. $^{49}$

Another recent initiative is the implementation of the 'Streets Ahead' project taking place in the Victoria and Angelsey wards in Burton-on-Trent. As highlighted earlier, both of these areas are populated by a number of ethnic minorities and by taking the projects into these communities it is felt prevents the barriers identified by Collins from being used as a reason for non-participation. ${ }^{50}$ The project was awarded $£ 40,000$ over two years by the Staffordshire Children’s Fund and is free to all those eligible to take part. The aim of this project is to provide physical activities to young people aged 6-16, with good access to high quality leisure, cultural and sporting experiences. It is delivered during the evenings with the aim of providing a safe environment as well as encouraging greater use of children's time. Activities are adapted to the street and include football, cricket, basketball, hockey and handball and street dance.

Again concurring with the thoughts of Coalter, with a similar proactive approach, in Stoke-on-Trent, a more national project 'StreetGames' is being delivered to lots of different wards in the city, including those with a high number of ethnic minorities. This was established in 2006 to promote participation in sport for young people living in the most disadvantaged communities. The project is aimed at the 7-25 age group with a target to get nearly 3,000 engaged in regular positive activity. Other objectives within the project include attracting 320 new volunteers aged over 16, 320 people benefiting from access to nationally accredited leadership training, and a further 40 gaining employment as sports coaches/leaders. ${ }^{51}$ In fact, the first phase was so successful that the second phase of the project began at the end of 2008. In 
addressing one of its objectives, due to high levels of attendance by those not eligible to take part (i.e. they are too old), such as mothers, fathers, brothers and sisters, the next stage is to encourage these individuals to become trained up to the Community Sports Leader Award (level 2) so that they can voluntarily assist in the local community.

Understandably the participants employed by the local authorities stressed a more proactive picture of local engagement with ethnic minorities. Concurring with the findings of Long et al., both authorities monitored participation rates by ethnic minorities with the sports development officer for managing 'StreetGames' at Stokeon-Trent City Council stating:

\begin{abstract}
it's important we get ethnic minorities involved in sport in this city. Statistics carried out nationally paint a worrying picture of physical activity levels in Stoke-on-Trent and as a local provider we need to keep this momentum going. It's hard, especially with the media painting this city as racist after the British National Party targeted it as a place to win votes politically, but we owe it to the ethnic minorities that they are welcome in this city and this type of project goes some way towards that.
\end{abstract}

However, both local authority employees did recognise that as well as low participation rates there remained a dearth of coaches from ethnic minority groups across both areas. Both local authorities only employed ethnic minority coaches on a casual basis so it was not surprising for them to acknowledge how this hampered the opportunity for the development of role models for younger ethnic minorities. ${ }^{52}$ Each participant stressed the importance of racial equality and how policies and projects were reflecting this approach but with no full-time roles for ethnic minority coaches it is unclear how effective the racial equality policies and objectives to begin increasing participation will be. ${ }^{53}$

To begin evaluating the actual impact of the projects across both areas, a small number of participants from group three were asked about the importance of them for ethnic minorities. In fact, all of the participants stated that the projects in operation were an important part of integrating ethnic minorities into sport with one participant involved in the 'Streets Ahead' project stating:

in the past I did not engage with physical activity on a regular basis due to a lack of free time and motivational laziness. However, now that different projects seem to be coming into our neighbourhoods it has given me an incentive to become physically active again. 
With regards to how the local authorities could engage with ethnic minorities better, three participants stressed the need for greater communication between the local authorities and ethnic minorities so that everyone knows how to get involved. For example, an active participant involved in the 'Streets Ahead' project suggested the need for:

a central advice centre or newsletters or e-mail contact with representatives of different groups within the local community. This would be a start in attempting to engage with ethnic minorities...ethnic minorities need to be better informed of activities and events than they are at present.

Moreover, another participant, involved in the 'StreetGames' project outlined the need to:

make facilities more accessible for ethnic minorities, provide more information, reduce the cost of some activities where possible and encourage the community to make better use of local parks as they are free to use...if parks were maintained better, were kept dog free and were patrolled better by the local authorities this would encourage more families to spend time in a local park and would encourage more people to actively exercise.

From a different perspective, another participant involved in the 'Streets Ahead' project stated:

there is the interest there from a number of different ethnic minorities. For me it's one of two things. Local authorities need to get into particular areas more and develop a way of letting people know what is going on. For some communities sport or physical activity is a sign of racial inequality and whilst I get the impression they would like to take part a large number still remain reluctant. A bit more encouragement and opportunity to take part might do the trick.

Supporting the literature discussed earlier by Collins, a participant in the 'Streets Ahead' project stated that although he could see more ethnic minorities taking part in sport the same barriers preventing participation, such as culture, cost, a lack of information and access to facilities remain a prohibitive factor. ${ }^{54}$ Similarly, a member of the Afghan society in Burton-on-Trent stated that whilst some community members had an interest in sport or physical activity it did not appear high on the list of their priorities. Here, he stated how:

parents view education and religion as more important to the development of their children and these are unfortunately viewed as a higher priority than sport is...I also presume a number of them do not want to place their children in a position where inequalities are prevalent. 
Although there has been an increasing focus given to generating greater levels of participation for ethnic minorities, a number of studies have recommended the need for better lines of communication and for more transparency regarding equality. ${ }^{55}$ Unfortunately, some of the participants in group one felt that a more inclusive strategy remained crucial if participation rates were to improve. For example, when probed about the local authority's provision for ethnic minorities in a wider sense, a senior member of the Pakistani Community Centre in Burton-on-Trent was quite vocal in his views. This particular individual felt that there was a lack of engagement with local ethnic minorities, despite the fact that there were facilities which the local authority could utilise better. In fact, after a visit to this particular centre, the opportunity for engagement was evident. It is home to youth clubs, women's groups, welfare associations, health initiatives, luncheon clubs, community education, sports clubs, drop-in facilities and information and advice centres. In response to a lack of suitable provision for young people, a Central Youth Club was established and has quickly become popular as it attracts dozens of young people who attend on a regular basis. The aim is to provide a safe environment where young people can gain informal education and enjoy social activities whilst supervised by adults. Young people get the opportunity to play computer games, pool, badminton, table tennis, hockey, football, cricket, darts and basketball and there are plans in place to build a sports centre on the same site. There is also an Asian Girls Group in a culturally appropriate environment where issues affecting Asian girls are discussed and support is given (as recommended by Wray). ${ }^{56}$

Indeed, these views were not just applicable to Burton-on-Trent as a senior member of the Pakistani community in Stoke-on-Trent felt that:

whilst I have to recognise the efforts of the local authority in attempting to engage with
the Pakistani community, better lines of communication and engagement in activities
within these communities would lead to greater levels of participation and activity.

Likewise, a lack of communication between ethnic minority groups and the local authority was also raised by a representative of the Queen Street Community Club in Burton-on-Trent. This, she claimed, was having a detrimental effect on the number of local residents (a) hearing about activities taking place and (b) then actually taking part in them. One of the centre's limitations is a lack of physical activity-based classes although they do run a Socatots session on a Saturday morning and it is involved with 
the 'Streets Ahead' project run by the local authority. Two out of the four sessions currently run by the 'Streets Ahead' project team are held at the Queen Street Community Centre, which is situated right in the heart of a ward heavily populated by ethnic minorities (Shobnall).

With similar views, although the Pakistani Community Centre in Burton-onTrent tried to cover a number of sports that appealed to the local community, a senior member felt that a lack of available facilities in the wider community detracted in persuading more to participate. Again supporting the literature discussed earlier, a lack of communication and promotion of activities was raised with a lack of provision for Asian sport (the opposite to Birmingham it was suggested) and limited material available regarding racial equality. ${ }^{57}$ Interestingly, this participant also stated the difficulty in gaining access to funds, which could further eliminate the Asian community from active sports participation.

Encouragingly, those who worked in the Pakistan Community Centres in both Burton-on-Trent and Stoke-on-Trent were all volunteers. However, for other ethnic minorities the need for more funding and the worryingly low number of active volunteers was raised. ${ }^{58}$ A senior member of the Indian community in Stoke-on-Trent stated how this undermined the opportunities for the Indian community to take part in physical activity as the lack of Indian volunteers meant a lack of role models for youngsters to aspire to. Adding to this is the greater demand now placed upon coaches and administrators involved in volunteering to demonstrate high levels of professionalism, knowledge and skills. Despite the efforts of the local authorities discussed earlier, in particular communities where sport is not of high cultural value, this seriously undermines the opportunities to recruit ethnic minority volunteers.

With regards to evidence of racial inequalities in a managerial sense, a representative from the Queen Street Community Centre in Burton-on-Trent illustrated the level of ethnic minority representation in the organisation. Only one (out of twelve) board members came from an ethnic minority and could support her comment that 'it is seen as a white centre'. Thus, as recommended by Hylton, the continued significance of 'whiteness' in the power structure of organisations and community centres gives further weight to the need for critical race theory to be treated seriously. ${ }^{59}$ To being combating racist ideologies and inequalities, ethnic minorities need to be incorporated into senior, more powerful, positions within sports organisations and local authorities have a significant role to play in this. 
As well as the two main projects being run in particular wards in both Burtonon-Trent and Stoke-on-Trent there are other examples of success. These include the establishment of Madina, an Asian sports club in Burton-on-Trent and Grange Park Rangers, an Asian football club in Stoke-on-Trent. Research has suggested that many ethnic minorities established their own teams to protect themselves from racism. ${ }^{60}$ However, representatives of both clubs suggest the breaking down of perceived barriers facing Asians in sport and state that the amount of racist acts they have witnessed has dramatically fallen over the years. Both clubs now feel more accepted in the wider sporting community and see themselves as good examples of how Asians can get involved and realise the personal benefits that engaging in sport or physical activity can bring to their lives.

\section{Conclusion}

Based on the research findings a number of conclusions can be drawn from this article. From a policy perspective, it has highlighted how two local authorities in the UK have started to be proactive by developing strategies and projects to engage with ethnic minorities. These include the 'StreetGames' project currently being run in Stoke-on-Trent and the 'Streets Ahead' project currently being run in Burton-onTrent. These two initiatives are needed in both areas as active participation in sport and physical activity for ethnic minorities remains low. Although at an early stage of development, by taking sport and physical activities into wards which are populated by a large number of ethnic minorities negates the barriers of travelling and cost becoming factors for non-participation. This might encourage more of the local community to become involved in voluntary work and possible future training; each of which assists the local authorities in meeting their objectives.

Although there has been progress in mixing participation between ethnic minorities and whites, this does not mean that the problems of racial inequalities and discrimination have been eliminated. The in-depth interviews with those involved in the ethnic minority community proved this. Thus, although there are policies in place and progress has been made, local authorities in particular still need to tackle racial inequalities better than they are at present and begin to fully understand the impact of social exclusion on ethnic minorities.

Overall, this article has illustrated how sport is facing a tough challenge of releasing the shackles of a discriminatory historic past. Through this, individual views 
and beliefs were shaped in ways which has allowed racial inequalities to remain at the forefront of society for a long time and for which certain institutions (such as sport) has found difficult to eradicate. If greater changes are to occur, it will need local authorities to proactively seek new ways of engaging with ethnic minorities through more inclusive projects and equality policies. Future research can continue to assess whether these are being achieved and how successful they are in meeting their objectives.

\section{Acknowledgements}

I would like to thank the two anonymous reviewers for their insightful and helpful thoughts on an earlier draft of this article.

\footnotetext{
${ }^{1}$ See, for example, Carrington and McDonald, 'Whose Game is it Anyway? Racism in Local League Cricket'; King, Offside Racism: Playing the White Man; Burdsey, British Asians and Football: Culture, Identity, Exclusion.

${ }^{2}$ Baglihole, Equal Opportunities and Social Policy: Issues of Gender, Race and Disability.

${ }^{3}$ Burdsey, British Asians and Football: Culture, Identity, Exclusion, 11.

${ }^{4}$ Miles and Brown, Racism.

${ }^{5}$ Garner, Racisms.

${ }^{6}$ Ibid, 17.

${ }^{7}$ Swinney and Horne, 'Race Equality and Leisure Policy Discourses in Scottish Local Authorities'.

${ }^{8}$ See Rowe and Champion, Sports Participation and Ethnicity in England: National Survey 1999/2000.

${ }^{9}$ Sport England, Active People 2 Survey.

${ }^{10}$ Ibid.

${ }^{11}$ Sporting Equals, Briefing Paper - Ethnic Minorities and Physical Activity in the East Midlands.

${ }^{12}$ Sport England, Active People 2 Survey.

${ }^{13}$ Department of National Heritage, Sport: Raising the Game.

${ }^{14}$ Sporting Equals, Findings from the Racial Equality Survey of National Governing Bodies.

${ }^{15}$ Sporting Equals, Achieving Racial Equality: A Standard for Sport.

${ }^{16}$ Long et al., 'Promoting Racial Equality within Sports Organisations'.

${ }^{17}$ Coalter, A Wider Social Role for Sport.

${ }^{18}$ Horne, 'Local Authority Leisure Policies for Black and Ethnic Minority Provision in Scotland'; Swinney and Horne, 'Race Equality and Leisure Policy Discourses in Scottish Local Authorities'; Carrington and McDonald, 'Whose Game is it Anyway? Racism in Local League Cricket'; Long et al., Raising the Standard: An Evaluation of Progress; 'Promoting Racial Equality within Sports Organisations'; Spracklen et al., 'Managing and Monitoring Equality and Diversity in UK Sport: An Evaluation of the Sporting Equals Racial Equality Standard and its impact on Organisational Change'.

${ }^{19}$ Long et al., Raising the Standard: An Evaluation of Progress.

${ }^{20}$ Long et al., 'Promoting Racial Equality within Sports Organisations'.

${ }^{21}$ Ibid.

${ }^{22}$ Spracklen et al., 'Managing and Monitoring Equality and Diversity in UK Sport: An Evaluation of the Sporting Equals Racial Equality Standard and its impact on Organisational Change'.

${ }^{23}$ Horne, 'Local Authority Leisure Policies for Black and Ethnic Minority Provision in Scotland'; Swinney and Horne, 'Race Equality and Leisure Policy Discourses in Scottish Local Authorities'.

${ }^{24}$ Horne, 'Local Authority Leisure Policies for Black and Ethnic Minority Provision in Scotland'.

${ }^{25}$ Ibid.

${ }^{26}$ Swinney and Horne, 'Race Equality and Leisure Policy Discourses in Scottish Local Authorities'.

${ }^{27}$ Ibid.

${ }^{28}$ Spracklen et al., 'Managing and Monitoring Equality and Diversity in UK Sport: An Evaluation of the Sporting Equals Racial Equality Standard and its impact on Organisational Change’; King, Offside
} 
Racism: Playing the White Man; Long and Hylton, 'Shades of White: An Examination of Whiteness in Sport'.

${ }^{29}$ See King, Offside Racism: Playing the White Man; Burdsey, British Asians and Football: Culture, Identity, Exclusion; Carrington, 'Sport, Masculinity and Black Cultural Resistance'.

${ }^{30}$ Hylton, “"Race”, Sport and Leisure: Lessons from Critical Race Theory’.

${ }^{31}$ Ibid.

${ }^{32}$ Long and Hylton, 'Shades of White: An Examination of Whiteness in Sport'.

${ }^{33}$ Rowe and Champion, Sports Participation and Ethnicity in England: National Survey 1999/2000.

${ }^{34}$ Sport England, 2000.

${ }^{35}$ Cabinet Office, 2000.

${ }^{36}$ Carroll et al., 'Promoting Physical Activity in South Asian Women through 'Exercise on Prescription’’. Collins and Kay, Sport and Social Exclusion.

37 Carroll et al., 'Promoting Physical Activity in South Asian Women through 'Exercise on Prescription'”.

${ }^{38}$ Johnson, 'Perceptions of Barriers to Healthy Physical Activity among Asian Communities'.

${ }^{39}$ Collins and Kay, Sport and Social Exclusion.

${ }^{40}$ Rowe and Champion, Sports Participation and Ethnicity in England: National Survey 1999/2000.

${ }^{41}$ Wray, 'Connecting Ethnicity, Gender and Physicality'.

42 Carroll et al., 'Promoting Physical Activity in South Asian Women Through 'Exercise on Prescription'; Duval et al., Perceptions of Local Women about Physical Exercise Provision in Shelton, Tunstall, Burslem and Longton; Sporting Equals, Briefing Paper - Ethnic Minorities and Physical Activity in the East Midlands.

43 Carroll et al., 'Promoting Physical Activity in South Asian Women through 'Exercise on Prescription',

${ }^{44}$ Duval et al., Perceptions of Local Women about Physical Exercise Provision in Shelton, Tunstall, Burslem and Longton; Sporting Equals, Briefing Paper - Ethnic Minorities and Physical Activity in the East Midlands.

${ }^{45}$ Gratton and Jones, Research Methods for Sports Studies.

${ }^{46}$ Carrington and McDonald, 'The Politics of 'Race' and Sports Policy in the United Kingdom', 242.

${ }^{47}$ Miles and Huberman, Qualitative Data Analysis, 9.

${ }^{48}$ Coalter, A Wider Social Role for Sport.

${ }^{49}$ Horne, 'Local Authority Leisure Policies for Black and Ethnic Minority Provision in Scotland'.

${ }^{50}$ Coalter, A Wider Social Role for Sport; Collins and Kay, Sport and Social Exclusion.

${ }^{51}$ Coalter, A Wider Social Role for Sport.

${ }^{52}$ Long et al., Raising the Standard: An Evaluation of Progress.

53 As suggested by Carroll et al. 'Promoting Physical Activity in South Asian Women through 'Exercise on Prescription',

${ }^{54}$ Collins and Kay, Sport and Social Exclusion.

${ }^{55}$ See Long et al., Raising the Standard: An Evaluation of Progress; 'Promoting Racial Equality within Sports Organisations'; Horne, 'Local Authority Leisure Policies for Black and Ethnic Minority Provision in Scotland'; Swinney and Horne, 'Race Equality and Leisure Policy Discourses in Scottish Local Authorities'; Spracklen et al., 'Managing and Monitoring Equality and Diversity in UK Sport: An Evaluation of the Sporting Equals Racial Equality Standard and its impact on Organisational Change'.

${ }^{56}$ Wray, 'Connecting Ethnicity, Gender and Physicality’.

57 Ibid.

${ }^{58}$ As identified by Sport England, Active People 2 Survey.

${ }^{59}$ Hylton, “"Race”, Sport and Leisure: Lessons from Critical Race Theory’.

60 See Johal, 'Playing Their Own Game: A South Asian Football Experience'; Carrington and McDonald, 'Whose Game is it Anyway? Racism in Local League Cricket'. 


\section{References}

Baglihole, B. Equal Opportunities and Social Policy: Issues of Gender, Race and Disability. London: Longman, 1997.

Burdsey, D. British Asians and Football: Culture, Identity, Exclusion. London: Routledge, 2007.

Cabinet Office (2000) 'Minority Ethnic Issuers in Social Exclusion and Neighbourhood Renewal'. In Sport and Social Exclusion, edited by M. Collins and T. Kay, 129. London: Routledge, 2003.

Carrington, B. 'Sport, Masculinity and Black Cultural Resistance'. In The Sport Studies Reader, edited by A. Tomlinson, 298-303. London: Routledge, 2007.

Carrington, B. and McDonald, I. 'Whose Game is it Anyway? Racism in Local League Cricket'. In 'Race', Sport and British Society, edited by B. Carrington and I. McDonald, 50-69. London: Routledge, 2001.

Carrington, B. and McDonald, I. 'The Politics of 'Race' and Sports Policy in the United Kingdom'. In Sport and Society: A Student Introduction, $2^{\text {nd }}$ Edition, edited by B. Houlihan, 230-254. London: Sage, 2008.

Carroll, R., Ali, N. and Azam. N. 'Promoting Physical Activity in South Asian Women through 'Exercise on Prescription’'. Health Technology Assessment 6, 8 (2002): 1-99.

Coalter, F. A Wider Social Role for Sport. London: Routledge, 2007.

Collins, M. and Kay, T. Sport and Social Exclusion. London: Routledge, 2003.

Department of National Heritage. Sport: Raising the Game. London: HMSO, 1995.

Duval, L., Sampson, J. and Boote, E. Perceptions of Local Women about Physical Exercise Provision in Shelton, Tunstall, Burslem and Longton. Stoke-on-Trent: Staffordshire University, 2004.

Garner, S. Racisms: An Introduction. London: Sage, 2009.

Gratton, C. and Jones, I. Research Methods for Sports Studies. London: Routledge, 2004.

Horne, J. 'Local Authority Leisure Policies for Black and Ethnic Minority Provision in Scotland'. In Policy and Politics in Sport, Physical Education and Leisure, edited by S. Fleming, M. Talbot and A. Tomlinson. Eastbourne: LSA publication no. 55, (1995): 159-176.

Hylton, K. “"Race”, Sport and Leisure: Lessons from Critical Race Theory’. Leisure Studies 24, 1 (2005): 81-98.

Long, J.A., Robinson, P. and Welch, M. Raising the Standard: An Evaluation of Progress. Leeds: Coachwise, 2003.

Long, J., Robinson, P., and Spracklen, K. 'Promoting Racial Equality within Sports Organisations'. Journal of Sport and Social Issues 29, (2005): 41-59.

Long, J. and Hylton, K. 'Shades of White: An Examination of Whiteness in Sport'. Leisure Studies 21, 2 (2002): 87-103.

Johal, S. 'Playing Their Own Game: A South Asian Football Experience'. In 'Race', Sport and British Society, edited by B. Carrington and I. McDonald, 153-169. London: Routledge, 2001.

Johnson, M.R. 'Perceptions of Barriers to Healthy Physical Activity among Asian Communities'. Sport, Education and Society 51, 1 (2000): 51-70. 
King, C. Offside Racism: Playing the White Man. Oxford: Berg, 2004.

Miles, R. and Brown, M. Racism. $2^{\text {nd }}$ Edition. London: Routledge, 1993.

Miles, M.B. and Huberman, M.A. Qualitative Data Analysis. London: Sage, 1984.

Rowe, N. and Champion, R. Sports Participation and Ethnicity in England: National Survey 1999/2000. London: Sport England, 2000.

Sport England. Active People 2 Survey. London: Sport England, 2008.

Sport England (2000). 'The use and management of sports halls and swimming pools in England 1997'. In Sport and Social Exclusion, edited by M. Collins and T. Kay, 127-132. London: Routledge, 2003.

Sporting Equals. Findings from the Racial Equality Survey of National Governing Bodies. London: Sport England, 1999.

Sporting Equals. Achieving Racial Equality: A Standard for Sport. London: Sport England, 2000.

Sporting Equals. Briefing Paper - Ethnic Minorities and Physical Activity in the East Midlands, 2007. Available at:

www.sportingequals.org.uk/DynamicContent/Documents/BriefingPapers/East_Midlands_briefing_pap er.pdf (accessed 15 April 2009).

Spracklen, K., Hylton, K. and Long, J. 'Managing and Monitoring Equality and Diversity in UK Sport: An Evaluation of the Sporting Equals Racial Equality Standard and its impact on Organisational Change'. Journal of Sport and Social Issues 30, 3 (2006): 289-305.

Swinney, A. and Horne, J. 'Race Equality and Leisure Policy Discourses in Scottish Local Authorities'. Leisure Studies 24, 3 (2005): 271-289.

Wray, S. 'Connecting Ethnicity, Gender and Physicality'. In Gender and Sport: A Reader, edited by S. Scraton and A. Flintoff, 141-155. London: Routledge, 2002. 